\title{
Reduction of tsunami inundation by coastal forests in Yogyakarta, Indonesia: a numerical study
}

\author{
W. Ohira ${ }^{1}$, K. Honda ${ }^{2}$, and K. Harada ${ }^{3}$ \\ ${ }^{1}$ School of Engineering and Technology, AIT, Pathumthani, Thailand \\ ${ }^{2}$ Chubu Institute for Advanced Studies, Chubu University, Aichi, Japan \\ ${ }^{3}$ Center for Integrated Hazards Research and Education, Shizuoka University, Shizuoka, Japan
}

Correspondence to: W. Ohira (wataru.ohira@ait.ac.th)

Received: 30 April 2011 - Revised: 14 November 2011 - Accepted: 16 November 2011 - Published: 11 January 2012

\begin{abstract}
Coastal forests are known to protect coastal areas from environmental degradation. In this paper, we examined another important role of coastal forests - to mitigate tsunami devastations to coastal areas. Using a twodimensional numerical model (Harada and Imamura model, 2005), we evaluated the damping effects of a coastal forest to resist tsunami inundation in Yogyakarta, Indonesia. In the simulations, we set up a two-km long control forest with a representative topography of the study site and experimented its damping performance sensitivity under various width configurations, e.g. 20, 40, 60, 80, 100 and $200 \mathrm{~m}$. The initial tsunami wave was set such that the inundation depth at the front edge of the forest would not exceed $4 \mathrm{~m}$ (tree fragility limit). The forest variables such as species, density, DBH, height and canopy size were determined from a typical forest of the site (Casuarina plantation, 4 trees $/ 100 \mathrm{~m}^{2}$, Diameter at Breast Height $=0.20 \mathrm{~m}$ ). The results showed that coastal forest with $100 \mathrm{~m}$ width reduced inundation flux, depth and area by 17.6, 7.0 and 5.7\%, respectively. Exponential models were found to describe the relationships between forest width and tsunami inundation transmission. An additional experiment was performed using actual topography and a forest plantation plan with $100 \mathrm{~m}$ width for $2.46 \mathrm{~km}^{2}$. In this experiment, the results showed that the plan would reduce inundation flux by $10.1 \%$, while the exponential model estimated it to be $10.6 \%$, close to the numerical model results. It suggests that statistical models of forest width and damping effects are useful tools for plantation planning, as it allows for quicker evaluation of the impact of coastal forest without simulation modeling that requires a lot of data, time and computing power.
\end{abstract}

\section{Introduction}

Tsunamis are an ever-present threat to lives and properties along the coastlines of the world. For this reason, we need to be proactive in developing ways on how to reduce the impact of tsunamis to these vulnerable areas. Mitigation of the impact of tsunami inundation is one of the expected functions of coastal forests. However, this has not been clearly understood and verified in the past, because of the difficulty in gathering evidences of the effects of the function and there are not enough field research data due to low frequency of tsunami occurrence (Kanamori, 1972).

Fragility functions of trees, e.g. Japanese black pine ( $P i$ nus thunbergii) and mangrove, for tsunami inundation were proposed based on the works of Shuto (1987) and Yanagisawa et al. (2009). They found that the hydraulic drag of trees is significant when DBH (diameter at breast height) is more than $0.15 \mathrm{~m}$, and the tsunami inundation depth does not exceed $4 \mathrm{~m}$. When the inundation depth exceeds $4 \mathrm{~m}$, there is a lesser chance for the forest to survive. Hence, the relationship between the damping performance of coastal forest generated by fluid resistance and physical form of trees should be studied within fragility limit.

Manning's roughness coefficient $(n)$ has been used to study surface resistance from different land cover in tsunami inundation simulations. Kotani et al. (1998) proposed the use of a higher Manning $n$ value for coastal forest than those for other land cover types, such as sand, bare land and grassland. Aburaya and Imamura (2002) modeled an equivalent roughness coefficient using a stand volume of coastal forest. In order to evaluate the hydrodynamic resistance of trees independently from surface resistance, Harada and Imamura (2005) 
modeled drag coefficient of trees as a function of tree volume based on hydrodynamic model experiments. They examined the relationships between the distance of inundation from Japanese black pine forest with $200 \mathrm{~m}$ width and found reductions. They indicated the reduction ratios against $3 \mathrm{~m}$ of tsunami height were $36 \%$ in run-up distance, $50 \%$ in inundation depth, $66 \%$ in current, and $92 \%$ in hydraulic force. Furthermore, using the same drag coefficient model, Yanagisawa et al. (2009) observed $26 \%$ reduction ratio of inundation depth and $57 \%$ of hydraulic pressure at a point behind $400 \mathrm{~m}$ wide mangrove forest (Rhizophora sp.) with $3 \mathrm{~m}$ incident wave. Although both studies discussed damping performance quantitatively, the studies were conducted in 1-Ddomain. For practical planning of coastal forest conservation and plantation, the study should be expanded into 2-Ddomain. This study aims to establish the relationship between tsunami inundation damping performance of coastal forest and its width in 2-D-domain. We applied the 2-Dmodel in a representative topography of the coastal area of Yogyakarta, and examined the damping effect of a planned plantation plan in the study area, and we compared the result with a quick view derived from the relationship.

\section{Methods}

\subsection{Numerical model}

We simulated tsunami inundation using a 2-D-numerical model set up with and without trees configurations; the difference between the results is known as the damping effect/performance of coastal forests. In conventional tsunamisimulation techniques for near coastal area, simplifications have been made with the shallow water hydrodynamics equation:

$$
\begin{aligned}
& \frac{\partial \eta}{\partial t}+\frac{\partial M}{\partial x}+\frac{\partial N}{\partial y}=0 \\
& M=\int_{-h}^{\eta} u_{x} d z=\bar{u}_{x} \times D \\
& N=\int_{-h}^{\eta} u_{y} d z=\bar{u}_{y} \times D \\
& D=\eta+h
\end{aligned}
$$

where

$\eta$ : wave height, $u$ : velocity, $M, N$ : flux for $\mathrm{x}$ and y direction, $D$ : total water depth and $h$ : depth of the sea.

Momentum equation with Manning and forest resistance terms are built in as seen below:

$$
\begin{aligned}
& \frac{\partial M}{\partial t}+\frac{\partial}{\partial x}\left(\frac{M^{2}}{D}\right)+\frac{\partial}{\partial y}\left(\frac{M N}{D}\right) \\
& +g D \frac{\partial \eta}{\partial x}+\frac{g n^{2}}{D^{7 / 3}} M \sqrt{M^{2}+N^{2}}+f_{x}=0
\end{aligned}
$$

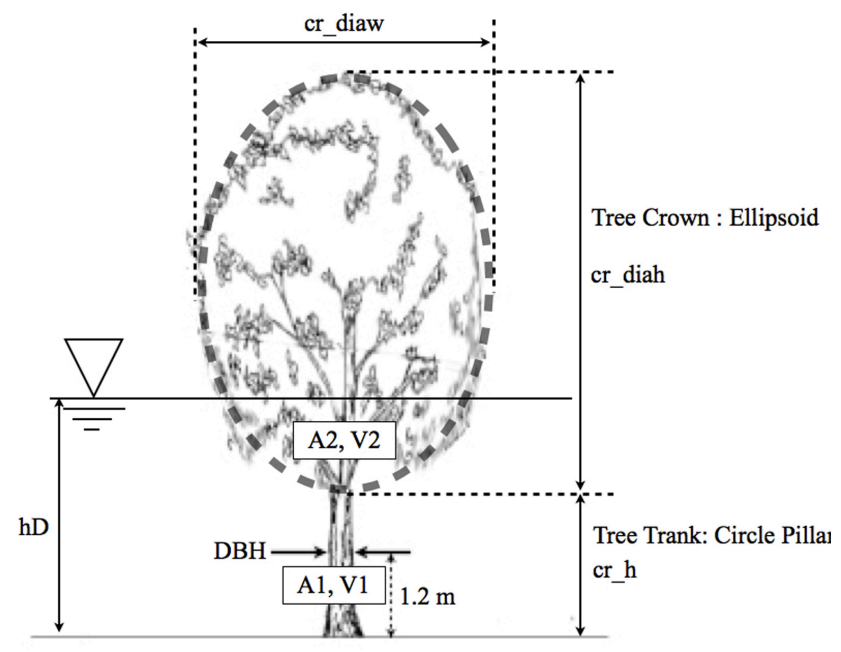

Fig. 1. Input factors of tree form.

$$
\begin{aligned}
& \frac{\partial N}{\partial t}+\frac{\partial}{\partial x}\left(\frac{M N}{D}\right)+\frac{\partial}{\partial y}\left(\frac{N^{2}}{D}\right) \\
& +g D \frac{\partial \eta}{\partial y}+\frac{g n^{2}}{D^{7 / 3}} N \sqrt{M^{2}+N^{2}}+f_{y}=0
\end{aligned}
$$

where $n$ : Manning's roughness coefficient, $f_{x}, f_{y}$ : resistance force from forest in $\mathrm{x}$ and $\mathrm{y}$ directions, and $g$ : gravity.

Harada and Imamura (2005) conducted hydraulic experiments with stiff model trees and other model objects and obtained drag coefficient $C_{\mathrm{D}}$ of forest as a function of the tree volume. This drag coefficient of forest was used to calculate hydrodynamic resistance generated by trees independently from Manning's surface resistance. Equation (9) indicates minimum $C_{\mathrm{D}}$ of the tree is 0.66 and the $C_{\mathrm{D}}$ increases slightly with the increase of $V_{0} / V$. The resistance force from the forest becomes 0 when there is no tree in the model as projected area $A_{0}$ and volume $V_{0}$ of trees under water become 0 . In this study, the trees are supposed to be stiff during inundation. Manning's roughness coefficient is used to estimate the friction between water and the bottom surface. Different surface types have different coefficient values, and empirically proposed values have been commonly used. The bottom surface of the study area is mostly sand, thus Manning's roughness coefficient is about 0.025 (Bernard, 2009; Aburaya and Imamura, 2004). The resistance forces from forest in $\mathrm{x}$ and $\mathrm{y}$ directions are shown below:

$f_{x}=\frac{C_{\mathrm{D}}}{2} \frac{A_{0}}{\Delta x \times \Delta y} \frac{M \sqrt{M^{2}+N^{2}}}{D^{2}}+C_{M} \frac{V_{o}}{V} \frac{\partial M}{\partial t}$

$f_{y}=\frac{C_{\mathrm{D}}}{2} \frac{A_{0}}{\Delta x \times \Delta y} \frac{N \sqrt{M^{2}+N^{2}}}{D^{2}}+C_{M} \frac{V_{o}}{V} \frac{\partial N}{\partial t}$

$C_{\mathrm{D}}=8.4\left(\frac{V_{o}}{V}\right)+0.66 \quad\left(0.01 \leq \frac{V_{o}}{V} \leq 0.07\right)$ 


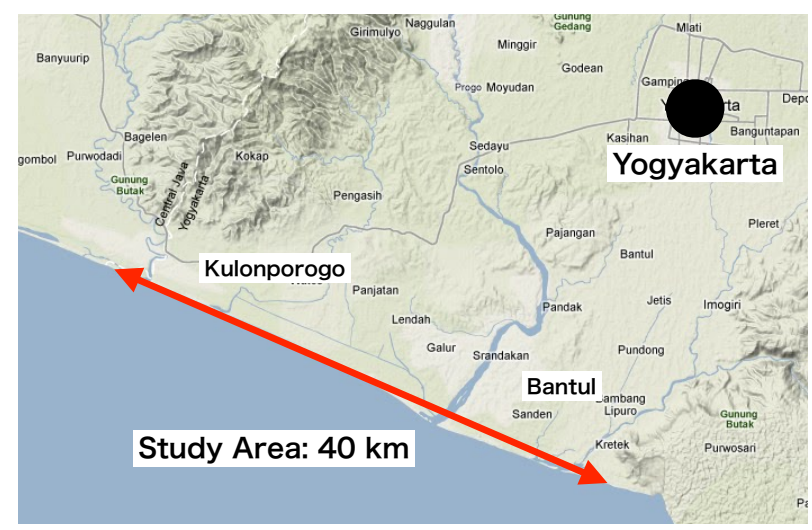

Fig. 2. Study area in Yogyakarta, Indonesia.

$C_{M}=1.7$

where $C_{\mathrm{D}}$ : drag coefficient, $C_{M}$ : inertia coefficient, $A_{0}$ : effective projected area of trees under water, $\mathrm{V}_{o}$ : effective body mass of trees under water, $V$ : volume of water, and $\Delta x, \Delta y$ : length in $\mathrm{x}$ and $\mathrm{y}$ direction of control volume. Tree shape and parameters are shown in Fig. 1.

$A_{0}=A_{1}+A_{2}^{\prime}$

$V_{0}=V_{1}+V_{2}^{\prime}$

$A_{1}=h_{\mathrm{D}} \mathrm{DBH}\left(\frac{d}{100} \Delta x \Delta y\right)$

$V_{1}=h_{\mathrm{D}} \pi \frac{\mathrm{DBH}^{2}}{4}\left(\frac{d}{100} \Delta x \Delta y\right)$

$A_{2}^{\prime}=A_{2}\left(1-S_{V}\right)^{2 / 3}$

$V_{2}^{\prime}=V_{2}\left(1-S_{V}\right)$

where $A_{1}$ : contribution of tree trunk to $A_{0}, A_{2}^{\prime}$ : contribution of tree canopy to $A_{0}, V_{1}$ : contribution of tree trunk to $V_{0}, V_{2}$ : contribution of tree canopy to $V_{2}^{\prime}, h_{\mathrm{D}}$ : water depth $\left(0<h_{\mathrm{D}}<\mathrm{cr}\right.$ h + cr_diah $), d$ : number of tree in $100 \mathrm{~m}^{2}, \mathrm{cr} \mathrm{h}$ : clear height of tree, cr_diah: size of tree canopy (height), cr_diaw: size of tree canopy (width), DBH: diameter of tree trunk, $A_{2}$ : projected area of tree canopy to the flow direction under water in a control volume, $V_{2}$ : volume occupied by tree canopy under water in a control volume (tree canopy is assumed to be an ellipsoid with cr_diah and cr_diaw), and $S_{V}$ : porosity of tree canopy. The tree canopy has low contribution to hydraulic drag, because in this precondition the inundation depth at the forest was less than $4 \mathrm{~m}$ and the trees had more than $3.2 \mathrm{~m}$ of clear height. Even when the clear height of the tree was low, a canopy porosity of 0.97 was estimated and applied for calculating the projected area and the volume (Harada and Imamura, 2002).

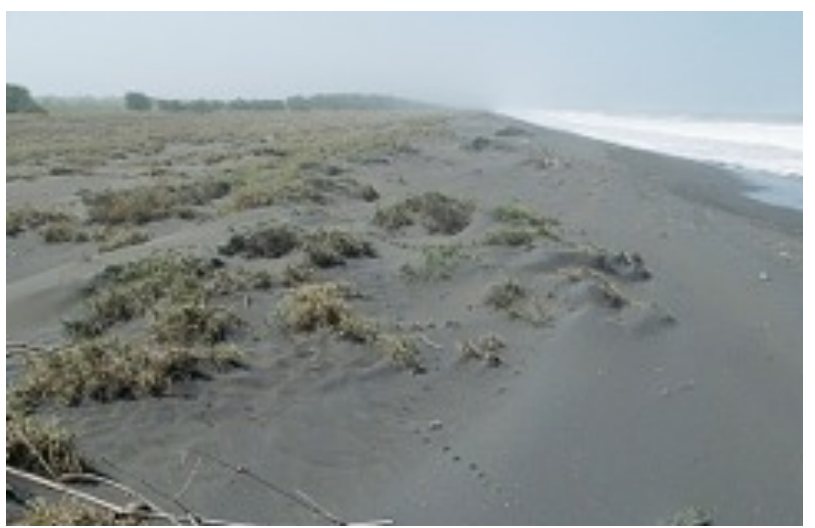

Fig. 3. Typical ground topography of the study area.

\subsection{Coastal area of Yogyakarta}

The study site is located at the southwestern part of Yogyakarta, Java, Indonesia. The coastline of approximately $40 \mathrm{~km}$ long, ranging from Kulonporogo to Bantul of Yogyakarta, was selected (Fig. 2). The coast is straight-line seashore, which mainly faces south-southwest. Low undulating sand dunes are extended approximately $1 \mathrm{~km}$ to $2 \mathrm{~km}$ towards inland along the coastline (Fig. 3). Farm lands and forests are the dominant land covers on the sand dunes. $\mathrm{Ca}$ suarina equisetifolia is the main tree species of the forests, followed by Acacia auriculiformis, and Acacia mangium. Slight differences in bathymetry were observed, as the west side of bathymetry slopes steeply down to offshore, but the eastern part slopes gradually downwards. However, the coast, as a whole, shows almost uniform bathymetric and ground topography. This coastal area has been attacked by tsunamis twice since 1994. The most recent attack was the Java tsunami in 17 July 2006, leaving approximately seven hundred dead and three hundred missing.

\subsection{Inundation simulation with control forests}

To establish the relationship between tsunami inundation damping effect and forest widths, the tsunami inundation simulations were conducted by changing the width of the control forest. A topography model was created based on typical bathymetric and ground topography of the study area with $10 \mathrm{~m}$ grid (Fig. 4). The tree species of the control forest was assumed to be Casuarina, which is a typical species in the coastal area. Parameters of the control forest were determined based on a field survey, e.g. 4 trees $/ 100 \mathrm{~m}^{2}$ with DBH of $0.20 \mathrm{~m}$, and a standardized tree height of $6 \mathrm{~m}$ with a canopy width of $3.9 \mathrm{~m}$. A 2-km long control forest with varying widths of $20,40,60,80,100$ and $200 \mathrm{~m}$ was set up respectively on the representative topography model at $50 \mathrm{~m}$ inland distance from the shoreline. An initial wave was set at a height of $3.5 \mathrm{~m}$ at the starting point, which generated an 


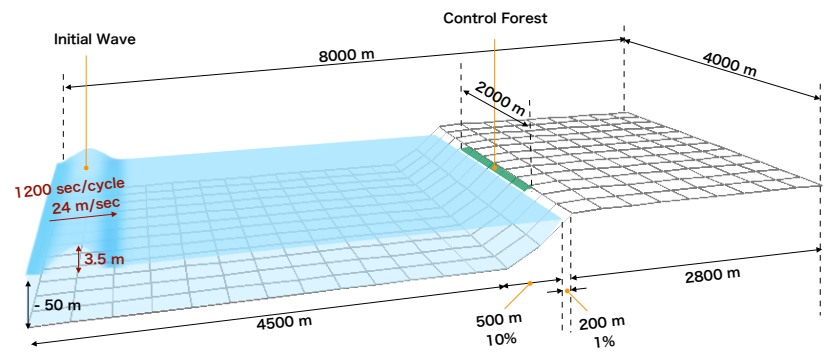

Fig. 4. Topography model for evaluating damping performance of control forests.

$8 \mathrm{~m}$ tsunami wave at the shoreline and the 4-m inundation depth at the front of the forest edge. The wave period was $1200 \mathrm{~s}$. Model state variables such as inundation depths and inundation flux (direction $\mathrm{x}$ and $\mathrm{y}$ ) of every second during $40 \mathrm{~min}$ were computed. The damping effect was quantified by comparing inundation states of each case behind the forest. Run-up distance was measured from the front edge of the center of the forest (sea side) to the end of the simulated inundation area where the maximum influence of the forest appears. The inundation area was measured as the area of the simulated inundation behind the forest (the area includes forest itself). Total flux is an absolute of flux for x-direction and y-direction. In this study, the inundation depth and the inundation flux for each case were defined as the average of maximum depth and total flux at each grid in the inundation area; these were within the 40 min of inundation time span. Then the transmission rate is defined by Eq. (17):

$r=\frac{T r}{n T r} \times 100$

where $r$ : transmission ratio (\%), $\operatorname{Tr}, n \operatorname{Tr}$ : value inundation states with and without trees (run up distance: $m$, inundation area: $\mathrm{km}^{2}$, inundation depth: $\mathrm{m}$, and inundation flux: $\left.\mathrm{m}^{2} \mathrm{~s}^{-1}\right)$.

\subsection{Inundation simulation for planned plantation}

An actual plantation plan was developed based on a field survey and land cover analysis of satellite images (Ohira et al., 2009). In order to evaluate the damping performance of the plan, we simulated the tsunami inundation using actual topography and land cover data for three cases, without any forest, with existing forest and with existing forest under the planned plantation.

The Casuarina plantation was planned at open spaces in $40 \mathrm{~km}$ of the coastline where the distance from the shoreline or riverside was $100 \mathrm{~m}$. The plantation assumed a DBH of $0.20 \mathrm{~m}, 4$ trees $/ 100 \mathrm{~m}^{2}$, width of $100 \mathrm{~m}$ and total length of $24.58 \mathrm{~km}$ (Fig. 5).

The topographic DEM (Digital Elevation Model) was derived from SPOT Enhanced DEM (20 m grid). The SPOT Enhanced DEM (SPOT DEM) was calibrated by subtracting

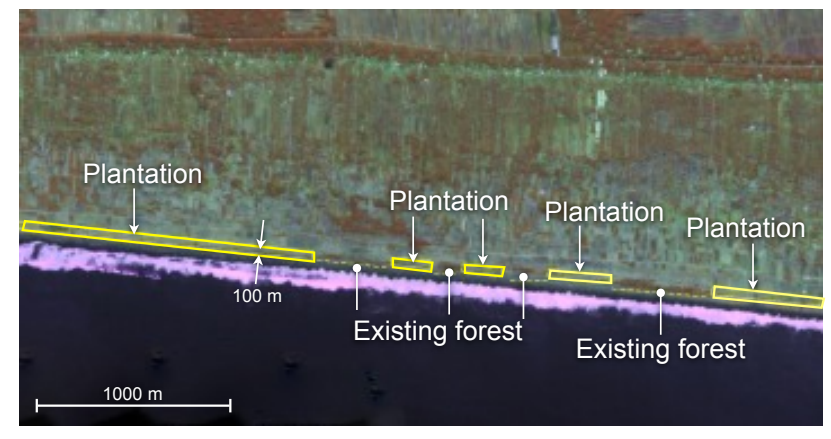

Fig. 5. Example of the planned plantation layout on the coastline.

$7.0 \mathrm{~m}$ referred by 665 points of a field level survey results. Using SPOT DEM, the $10 \mathrm{~m}$ interval contour lines were generated. The contour of $0 \mathrm{~m}$ was adjusted to the shoreline, which was detected on a SPOT5 image (27 June 2006). The bathymetric DEM was prepared from ETOPO 30 ( $3 \mathrm{~km}$ grid), and contour lines with an interval of $10 \mathrm{~m}$ were generated. The contour of $-20 \mathrm{~m}$ and $-10 \mathrm{~m}$ were adjusted to be parallel with the shoreline of the SPOT5 image, and the contour of $0 \mathrm{~m}$ was replaced with the contour of the land area. Finally, both of these contours were merged, and the entire DEM (20 m grid) of the computational domain was generated by natural neighbor interpolation method.

The land cover of 2006 was derived from a satellite imagery (SPOT5; 27 June 2006) by unsupervised classification, where misclassifications spots were revised by imagery interpretation (Fig. 6). The details of forest type such as species, tree density, DBH, tree height, canopy height and canopy width were obtained from 47 plots $(10 \mathrm{~m} \times 10 \mathrm{~m})$ during a field survey in June 2008. The DBH, one of the forest type parameters for numerical simulation, was examined against tree fragility under tsunami inundation. Shuto (1987) indicated the degree of damage to Pinus thunbergii using three categories: cut down, damage, and no damage. DBH of $0.1 \mathrm{~m}$ was indicated as a criterion of which trees will survive under an inundation of $4.65 \mathrm{~m}$. Harada and Imamura (2005) applied a $0.15 \mathrm{~m}$ DBH for $3 \mathrm{~m}$ inundation depth with $\mathrm{Pi}$ nus thunbergii to the numerical simulation, and Yanagisawa (2009) also applied the same criteria with Rhizophora. Ohira et al. (2009) showed the list of surviving coastal trees of Java tsunami in 2006 in Yogyakarta, Indonesia, with the minimum fragility line of $0.12 \mathrm{~m}$ of DBH for $4 \mathrm{~m}$ inundation depth. However, these values of DBH and the inundation depth are not definitive. In this study, a tree of more than $0.14 \mathrm{~m}$ of DBH was assumed to survive in $4 \mathrm{~m}$ of inundation depth. Accordingly, a tree having more than $0.14 \mathrm{~m}$ of $\mathrm{DBH}$ was the criterion to be a drag object. DBH and the tree density were calculated for trees with more than $0.14 \mathrm{~m}$ DBH. Then, five land cover classes such as "home garden", "coconut plantation", "Casuarina plantation", "Other trees/plantation" and "cultivated land with trees" acted as 


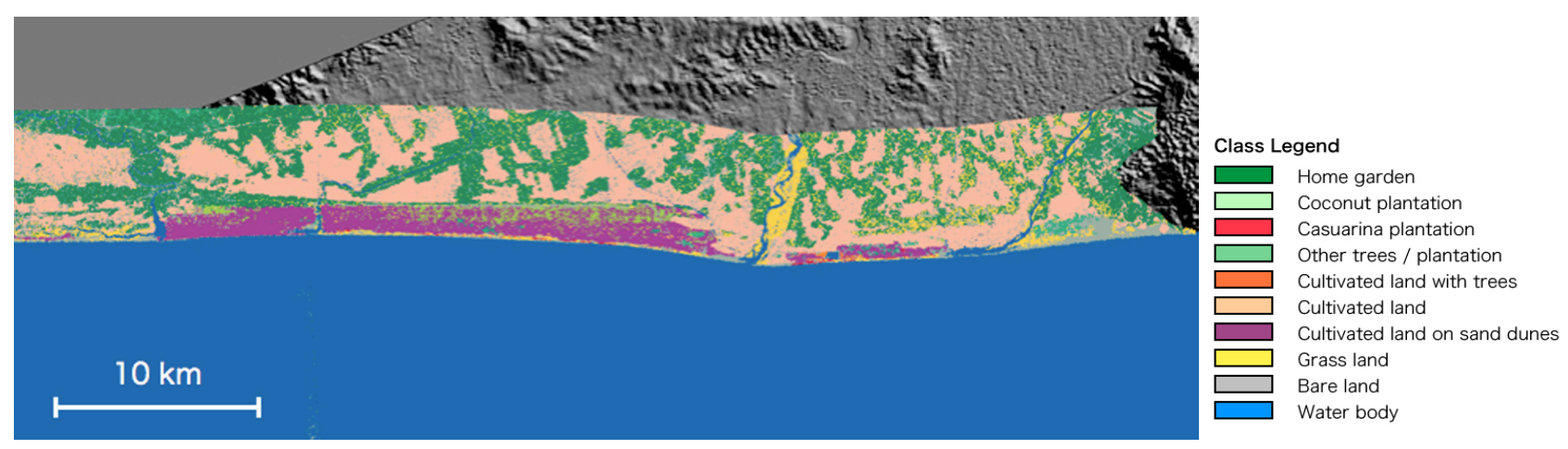

Fig. 6. Land cover/Land use classification using satellite imagery.

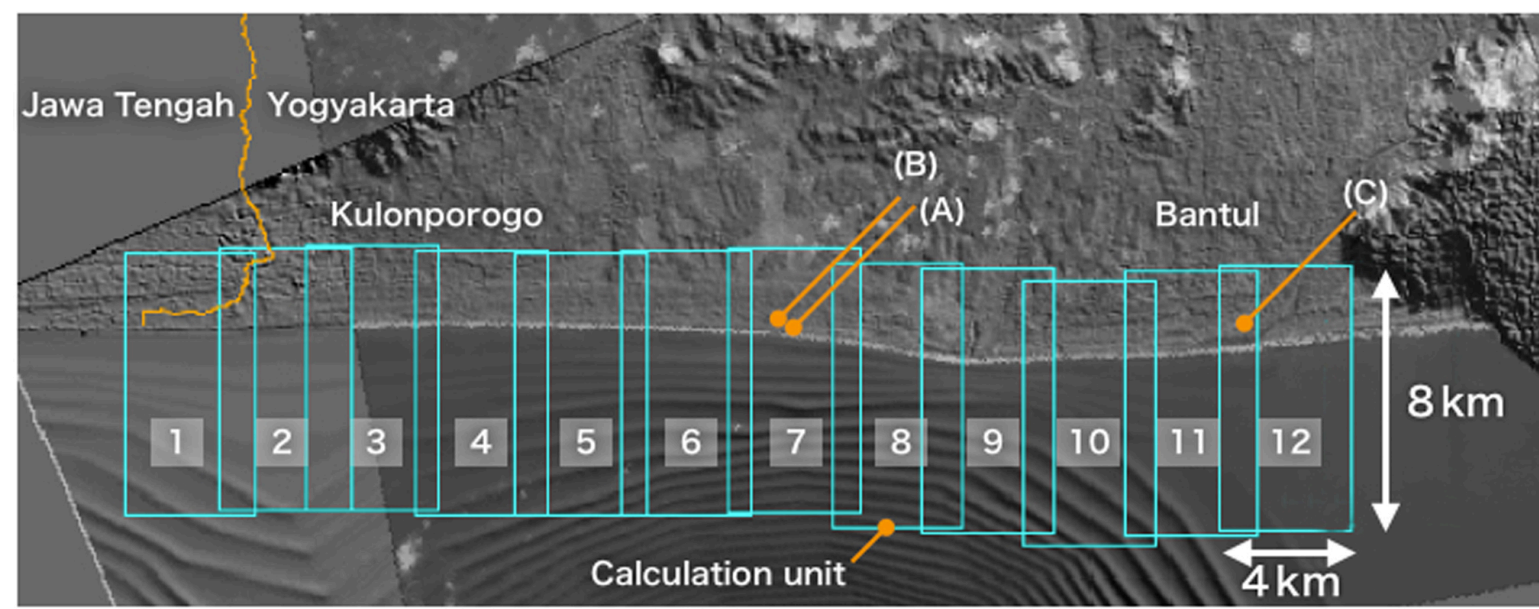

Fig. 7. Configuration of calculation units and the verification points (A), (B) and (C).

hydraulic drag with trees (Table 1). The tree canopy sizes were averaged values of the field records on each land cover class and a 0.97 porosity of tree canopy was applied (Harada and Imamura, 2002).

The twelve calculation control units $(4 \mathrm{~km} \times 8 \mathrm{~km})$ were set along the coastline due to constraints of computational time (Fig. 7). The computational time of one simulation was around $18 \mathrm{~h}$ with a $2.6 \mathrm{GHz} \mathrm{CPU}$. The wave period was decided as $20 \mathrm{~min}$, and maximum wave height at the shoreline as $8 \mathrm{~m}$ based on the Java tsunami 2006 testimony of the Regional Development Planning Board, Yogyakarta (Ohira et al., 2009). After that, the initial wave heights on each unit were separately derived from the pre-simulation results. In this condition, the inundation depth at the front edge of the forest did not exceed $4 \mathrm{~m}$, which is the tree fragility limit. The number of waves for the simulation was set as 1 due to computational time constraint.

The initial wave velocity was calculated from the water depth (the depth of the sea and the initial wave height, Eq.18) at wave start point in each unit (Table 2) thusly:

$u=\sqrt{g \times(h+\eta)}$

in which $u$ : initial wave velocity $\left(\mathrm{m} \mathrm{s}^{-1}\right)$.
In order to validate the model performance and parameter values, the simulated inundation depth was compared with field records obtained after the 1994 East Java Offshore Earthquake tsunami and the 2006 Java Southwest Offshore Earthquake tsunami (Fig. 7, Table 3), (BAPEDA, 2007). The inundation depth of past tsunamis in the Table 3 are averages of several records at each verification point.

\section{Results and discussions}

\subsection{Area of influence with the forest width}

The damping performance of coastal forests against tsunami inundation was evaluated using a 2-D simulation model by considering different forest width configurations. Figure 8 shows the area of influence in inundation depth by the different control forests. We indicated the area where inundation depth was more than $0.01 \mathrm{~m}$ because this value of depth influences the movement of people. The damping effect of forests is mainly observed at the area behind the forest, while the inundation depth tends to increase in the front side of the forest. The highest reduction in depth appeared just behind 
Table 1. The land cover/Land use parameters for the numerical simulation.

\begin{tabular}{lllllll}
\hline $\begin{array}{l}\text { Land cover } \\
\text { class }\end{array}$ & $\begin{array}{l}d \\
\left(\text { Trees } \times 10^{-2} \mathrm{~m}^{-2}\right)\end{array}$ & $\begin{array}{l}\text { DBH } \\
(\mathrm{m})\end{array}$ & $\begin{array}{l}\text { cr_h } \\
(\mathrm{m})\end{array}$ & $\begin{array}{l}\text { cr_diaw } \\
(\mathrm{m})\end{array}$ & $\begin{array}{l}\text { cr_diah } \\
(\mathrm{m})\end{array}$ & $S v$ \\
\hline Home garden & 4.15 & 0.25 & 9.7 & 8.1 & 5.5 & 0.97 \\
Coconut plantation & 3.78 & 0.26 & 3.8 & 7.9 & 6.5 & 0.97 \\
Casuarina plantation & 1.33 & 0.20 & 0.0 & 3.9 & 6.0 & 0.97 \\
Other trees/Plantation & 4.67 & 0.23 & 3.2 & 4.3 & 7.6 & 0.97 \\
Cultivated land with trees & 0.89 & 0.21 & 0.5 & 4.4 & 10.5 & 0.97 \\
Cultivated land & 0 & 0 & 0 & 0 & 0 & 0 \\
Cultivated land on sand dune & 0 & 0 & 0 & 0 & 0 & 0 \\
Grass land & 0 & 0 & 0 & 0 & 0 & 0 \\
Bare land & 0 & 0 & 0 & 0 & 0 & 0 \\
Water body & 0 & 0 & 0 & 0 & 0 & 0
\end{tabular}

Table 2. The initial wave setting for the calculation units.

\begin{tabular}{rrrrrr}
\hline $\begin{array}{r}\text { Unit } \\
\text { No. }\end{array}$ & $\begin{array}{r}\text { Water level at } \\
\text { the initial wave } \\
\text { start point }(\mathrm{m})\end{array}$ & $\begin{array}{r}\text { Initial wave } \\
\text { height } \\
(\mathrm{m})\end{array}$ & $\begin{array}{r}\text { Initial wave } \\
\text { velocity } \\
\left(\mathrm{m} \mathrm{s}^{-1}\right)\end{array}$ & $\begin{array}{r}\text { Wave period } \\
(\mathrm{s})\end{array}$ & $\begin{array}{r}\text { Number } \\
\text { of } \\
\text { waves }\end{array}$ \\
\hline 1 & -22 & 4.0 & 15 & 1200 & 1 \\
2 & -17 & 4.0 & 13 & 1200 & 1 \\
3 & -22 & 4.0 & 15 & 1200 & 1 \\
4 & -32 & 4.0 & 17 & 1200 & 1 \\
5 & -32 & 4.0 & 17 & 1200 & 1 \\
6 & -61 & 3.5 & 24 & 1200 & 1 \\
7 & -71 & 3.0 & 26 & 1200 & 1 \\
8 & -79 & 3.0 & 27 & 1200 & 1 \\
9 & -52 & 3.6 & 22 & 1200 & 1 \\
10 & -48 & 3.6 & 22 & 1200 & 1 \\
11 & -17 & 4.0 & 13 & 1200 & 1 \\
12 & -11 & 4.3 & 10 & 1200 & 1 \\
\hline
\end{tabular}

the center of the post edge of the forest, while the degree of reduction gradually reduced symmetrically towards both edges from the center of post edge of the forest (left and right in the figure). The shortest run-up distance appeared at the center of the forest. Figure 9 shows the area of influence of inundation flux by different control forests. Here, we indicated the area where the inundation flux difference was more than $0.01 \mathrm{~m}^{2} \mathrm{~s}^{-1}$. We set this threshold because this value of flux starts to influence the movement of people. The main reduction was found behind the forest, while slight reduction was observed in front of the forest. The maximum reduction of the flux is seen behind the center of post edge of the forest, and the damping effect decreases towards both edges of the forest. This behavior of influence is similar to influence in the inundation depth, but influenced area of the flux with the forest is much larger for the case of $20 \mathrm{~m}$ compared to the influence in depth (Fig. 10).

The damping effect of forest against tsunami inundation is more pronounced behind the forest, with the highest impact behind the center point of the forest. The damping area was extended with increasing forest width (for the inundation depth) while even with $20 \mathrm{~m}$ forest width, there was a considerable damping area observed in terms of inundation flux.

\subsection{Reduction of tsunami effects with the forest width}

The tsunami inundation flow decreases progressively with distance from the forest front. The inundation flow at each position includes the reduction effect as buffer space. Therefore, it is not necessarily appropriate to suggest that the difference of inundation state between two points is the damping effect caused only with the forest. In order to determine the damping performance of the forest, we compared average values of the inundation flow in the inundation area (Table 4).

Relative to the increase of forest width, the average transmissions of the inundation at the area behind the post edge of forest area is also reduced. The transmission through $200 \mathrm{~m}$ of the forest width shows $75.2 \%, 92.5 \%, 88.1 \%$ and $90.2 \%$ 
Table 3. Comparison of inundation depths of past tsunami and numerical model.

\begin{tabular}{lcc}
\hline $\begin{array}{l}\text { Verification } \\
\text { point }\end{array}$ & $\begin{array}{c}\text { Inundation depth } \\
\text { of past tsunami (m) }\end{array}$ & $\begin{array}{c}\text { Inundation depth } \\
\text { by numerical model (m) }\end{array}$ \\
\hline $\begin{array}{l}\text { (A) Near intake of the fish farm at Kabupaten Bantul } \\
\text { (B) Behind the fish farm at Kabupaten Bantul }\end{array}$ & 7.0 & 8.1 \\
(C) $800 \mathrm{~m}$ upstream from mouth of the k.Winoingo kecil River & 2.0 & 0.8 \\
\hline
\end{tabular}

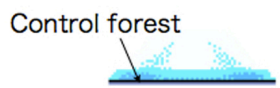

$20 \mathrm{~m}$

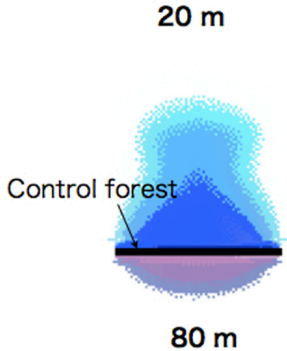

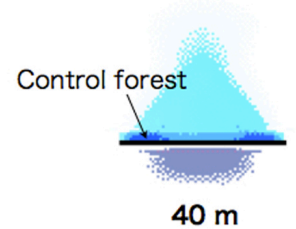

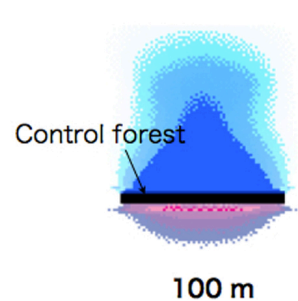

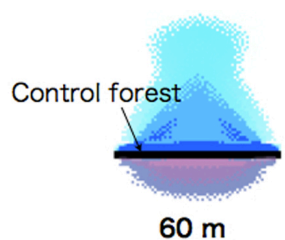

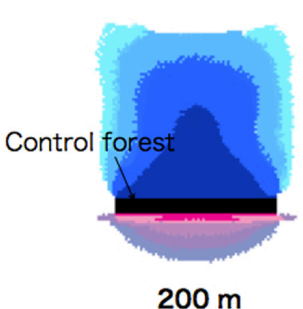

Water level change

(m)

$-0.3>n \geqq-0.4$

$-0.2>n \geqq-0.3$

$-0.1>n \geqq-0.2$

$-0.01>n \geqq-0.1$

$0.01<n \leqq+0.1$

$+0.1<\eta \leqq+0.2$

$+0.2<n \leqq+0.3$

$+0.3<n \leqq+0.4$

$+0.4<\eta \leqq+0.5$

Fig. 8. The differences in the inundation depth around the forest (with-without forest).

reduction in the inundation flux, depth, run-up distance, and area, respectively. The transmission of the inundation flux was clearly lower than the inundation depth (Fig. 11).

Harada and Imamura (2005) indicated $50 \%$ transmission of the inundation depth with $200 \mathrm{~m}$ forest width. The forest had high tree density of 30 trees $/ 100 \mathrm{~m}^{2}$ with $0.15 \mathrm{~m}$ of $\mathrm{DBH}$, and they measured at just behind the center of post edge of forest with $200 \mathrm{~m}$ forest width. The transmission result of this study is $93 \%$, with relatively large improvement from Harada and Imamura (2005). Although the measurement approach is different, the forest stand volume can also take a valuable contribution to the hydraulic drag. Hence, for the accurate estimation of tsunami inundation, not only forest expansion but also forest and stand volume are essential information.

The above relationships among forest width, transmission of run-up distance, inundation area, inundation depth and inundation flux are expressed in exponential functions as shown below:

$$
\begin{array}{ll}
\mathrm{RD}=e^{(-0.000542 x-0.019)} & 20 \leqq x \leqq 200\left(r^{2}=0.999\right) \\
\mathrm{IA}=e^{(-0.000504 x-0.0126)} & 20 \leqq x \leqq 200\left(r^{2}=0.989\right) \\
\mathrm{ID}=e^{(-0.000168 x-0.0462)} & 20 \leqq x \leqq 200\left(r^{2}=0.479\right) \\
F=e^{(-0.00105 x-0.0851)} & 20 \leqq x \leqq 200\left(r^{2}=0.987\right)
\end{array}
$$

where $x$ : forest width (m), RD: transmission of run-up distance, IA: transmission of inundation area, ID: transmission of inundation depth, and $F$ : transmission of inundation flux.

Transmission will be expected to reduce following a exponential curve if unit width of forest allow tsunami to transmit or absorb at a constant rate. Therefore, the exponential curves were applied to approximate the transmissions of forest up to $200 \mathrm{~m}$ width. In our case, the defined transmission is not at the post edge of the forest. However, the fitting of the exponential curves gave quite a high R-square value except for the transmission of inundation depth. These exponential functions could be used to estimate the damping capacity of forest without performing complicated simulation. The simple statistical models can contribute to practical coastal forest planning processes. Although the coefficient of each equation may vary according to local conditions, they may be applied in areas with similar characteristics.

\subsection{Expected damping performance with the forest plantation in Yogyakarta}

Tsunami inundation simulation for a wide area needs a complicated data preparation and long computational time. Quick damping assessment of tsunami inundation by forests may be needed at the early stage of coastal forest planning. We estimated the damping performance of the forest plantation at the coast of Yogyakarta by the numerical simulation and the exponential models described above. 


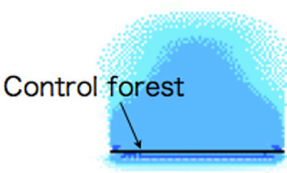

$20 \mathrm{~m}$

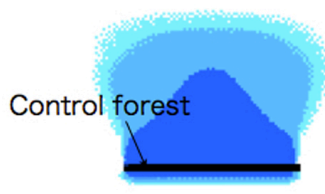

$80 \mathrm{~m}$

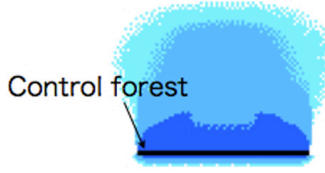

$40 \mathrm{~m}$

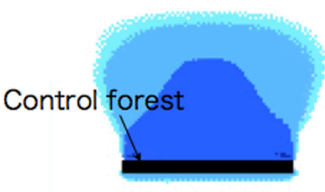

$100 \mathrm{~m}$

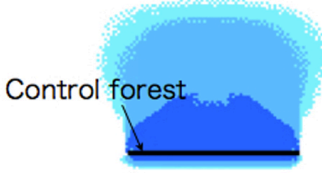

$60 \mathrm{~m}$

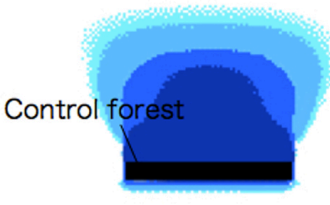

$200 m$
Reduced flux

$\left(\mathrm{m}^{2} / \mathrm{sec}\right)$

$3.0<\mathrm{RF} \leqq 4.0$

$2.0<\mathrm{RF} \leqq 3.0$

$1.0<\mathrm{RF} \leqq 2.0$

$0.0<\mathrm{RF} \leqq 1.0$

RF: Reduced flux

Fig. 9. The damping performance of forest for inundation flux around the forest.

Table 4. The forest widths and the transmission.

\begin{tabular}{|c|c|c|c|c|c|c|c|c|}
\hline \multirow{3}{*}{$\begin{array}{l}\text { Forest } \\
\text { width (m) } \\
\mathbf{2 0}\end{array}$} & \multirow{2}{*}{\multicolumn{2}{|c|}{$\frac{\text { Inundation flux }}{\left(\mathrm{m}^{2} \mathrm{~s}^{-1}\right) \text { Transmission }}$}} & \multirow{2}{*}{\multicolumn{2}{|c|}{$\begin{array}{l}\text { Inundation depth } \\
\text { (m) Transmission }\end{array}$}} & \multirow{2}{*}{\multicolumn{2}{|c|}{$\frac{\text { Inundation area }}{\left(\mathrm{km}^{2}\right) \text { Transmission }}$}} & \multirow{2}{*}{\multicolumn{2}{|c|}{$\frac{\text { Run-up distance }}{(\mathrm{km}) \text { Transmission }}$}} \\
\hline & & & & & & & & \\
\hline & 5.89 & $90.9 \%$ & 1.81 & $96.8 \%$ & 5.35 & $98.5 \%$ & 2.60 & $97.0 \%$ \\
\hline 40 & 5.67 & $87.5 \%$ & 1.76 & $94.1 \%$ & 5.28 & $97.2 \%$ & 2.57 & $95.9 \%$ \\
\hline 60 & 5.58 & $86.1 \%$ & 1.76 & $94.1 \%$ & 5.21 & $95.9 \%$ & 2.54 & $94.8 \%$ \\
\hline 80 & 5.42 & $83.6 \%$ & 1.75 & $93.6 \%$ & 5.16 & $95.0 \%$ & 2.52 & $94.0 \%$ \\
\hline 100 & 5.34 & $82.4 \%$ & 1.74 & $93.0 \%$ & 5.12 & $94.3 \%$ & 2.48 & $92.5 \%$ \\
\hline 200 & 4.87 & $75.2 \%$ & 1.73 & $92.5 \%$ & 4.90 & $90.2 \%$ & 2.36 & $88.1 \%$ \\
\hline
\end{tabular}

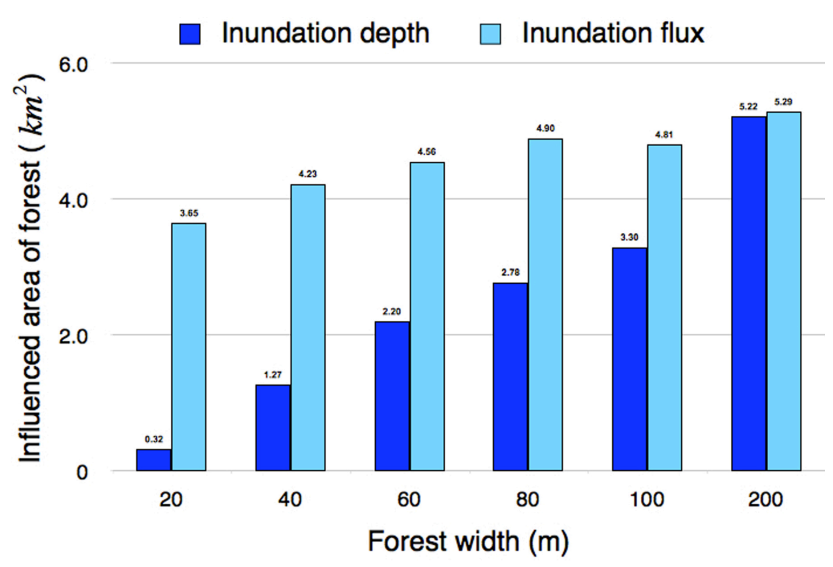

Fig. 10. The influenced area and the forest width.

Table 5 indicates the numerical simulation results of inundation area, depth and flux with three different surface conditions such as without trees, with trees in 2006 condition, and with the planned plantation of $100 \mathrm{~m}$ width (addition to the forest in 2006). The inundation depth and inundation flux are the average in the inundation area. The existing coastal forests reduced the transmission by 5.6, 0.0 and $7.0 \%$

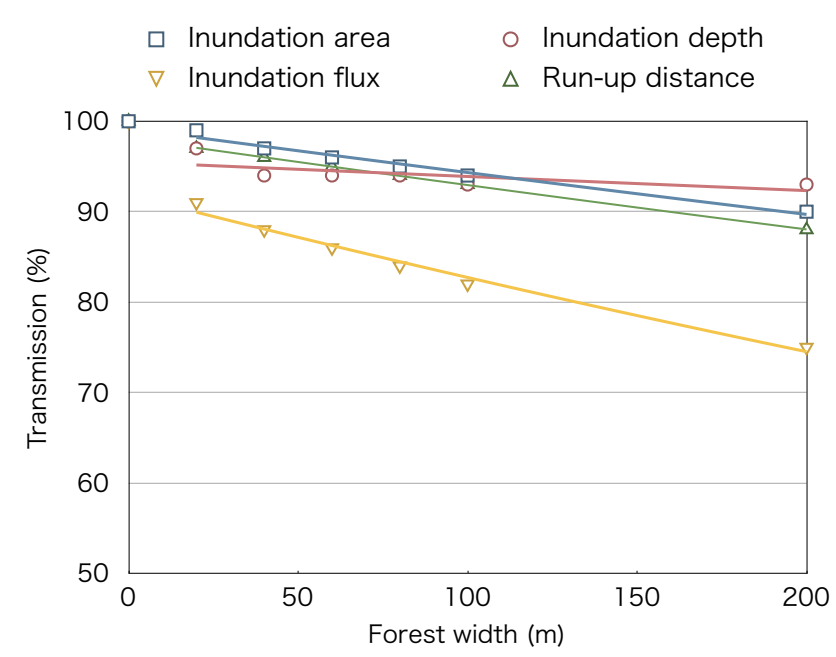

Fig. 11. The transmission of tsunami inundation with the forest width.

of inundation area, flux and depth, respectively; while the planned plantation could reduce the transmission by $7.1,4.9$ and $16.4 \%$ of inundation area, depth and flux, respectively. 
Table 5. The simulated damping performance of coastal forest in Yogyakarta.

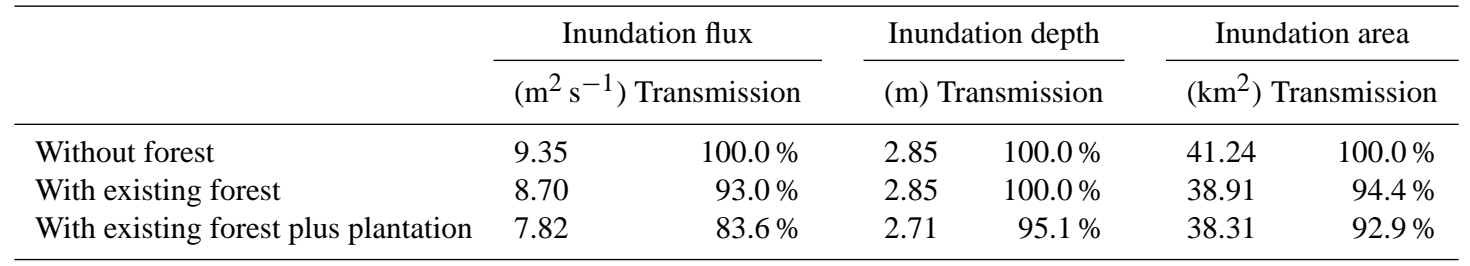

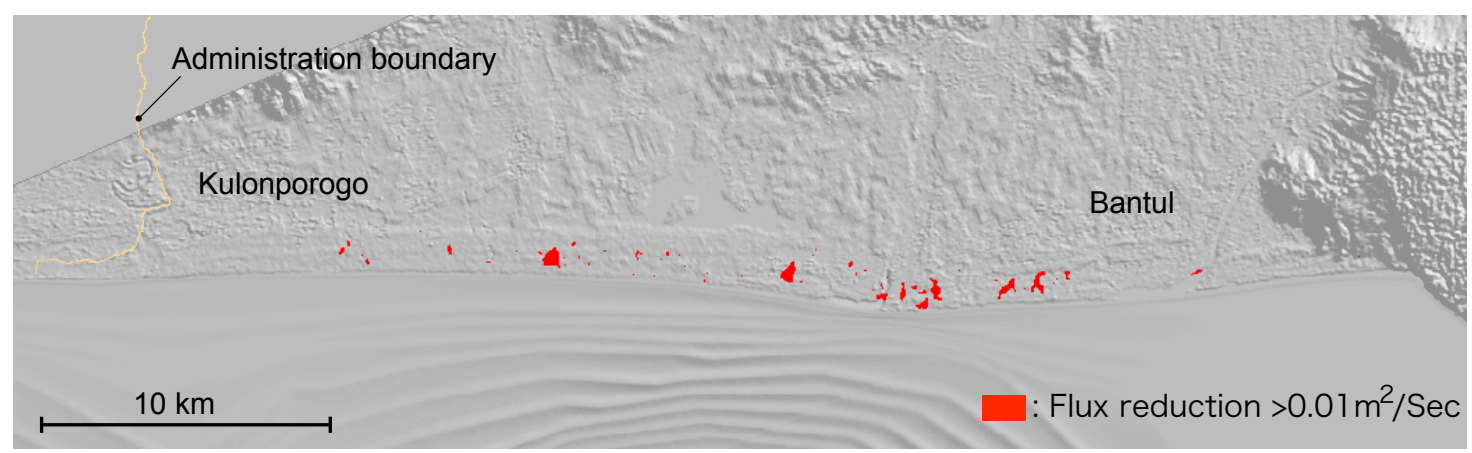

Fig. 12. The area of influence on inundation flux with the trees in 2006.

While the inundation flux reduction locally appeared at the area behind the post edge of forests in 2006, reduction of flux with the planned plantation extensively appeared at the area behind the post edge of forest for both the plantations and the forests (Figs. 12 and 13).

This numerical simulation scheme would overestimate the damping performance of forests if the tsunami wave was more than $4 \mathrm{~m}$. Tsunami wave will start to destroy the forest, which is not considered in the simulation. On the other hand, this scheme would underestimate the damping performance for small scale tsunamis, as we have neglected trees with DBH less than $0.14 \mathrm{~m}$ for drag calculation considering tree fragility. If the wave is lower than $4 \mathrm{~m}$, smaller trees should be taken into account for drag force calculation. In actual situations, there is not a clear threshold of wave height which destroys forests. As wave height increases, trees will start to bend and finally turn over, which happens to each individual tree according to the size of the tree. Fragility functions that take into account of the size of trees as well as bending behavior are necessary to establish a simulation scheme that has applicability in a broad range of input wave height.

Table 6 indicates the transmission reduction with the planned plantation by the numerical simulation and the exponential models. Total length of the existing forest in 2006 was $15.42 \mathrm{~km}$ out of $40 \mathrm{~km}$ total coast length, and average forest width was $40 \mathrm{~m}$. The transmissions with $40 \mathrm{~m}$ of the forest width were calculated as 88.1, 94.8 and $96.8 \%$ in inundation flux, depth, and area, respectively (Eqs. 22, 21, and
20). These transmissions are only for behind the existing forest. In order to obtain the contribution of these transmissions in total inundation area, we calculated the weighted average against the total coastline length using Eq. (23).

$T m=T m_{\text {exist }} \frac{L_{\text {exist }}}{L_{\text {cost }}}+T m_{\text {plan }} \frac{L_{\text {plan }}}{L_{\text {cost }}}$

where $T m$ : total transmission $(\%), T m_{\text {exist }}, T m_{\text {plan }}$ : transmission by existing forest and planned plantation by Eqs. (22), (21), and (20) (\%), $L_{\text {cost }}$ : total coast length $(40 \mathrm{~km})$, and $L_{\text {exist }}, L_{\text {plan }}$ : length of existing forest and planned plantation (15.42 and $24.58 \mathrm{~km}$ ) .

The total transmissions by existing forest were estimated as $95.4 \%$ in flux, $98.0 \%$ in depth, and $98.8 \%$ in area. The transmission by planned plantation of $100 \mathrm{~m}$ width forest were calculated as $89.4 \%$ in flux, $96.2 \%$ in depth, and $96.2 \%$ in area (Eqs. 22, 21, and 20). The total transmission with both the existing forest in 2006 and the plantation were $84.8 \%$ in flux, $94.2 \%$ in depth, and $95.0 \%$ in area.

On the other hand, the transmissions based on the simulation with the forest in 2006 were estimated as $93.0 \%$ in flux, $100 \%$ in depth, and $94.4 \%$ in area, while with both the existing forest in 2006 and the plantation, they were $83.6 \%$ in flux, $95.1 \%$ in depth, and $92.9 \%$ in area.

Finally, the transmission reductions in flux by the planned plantation were calculated as $9.4 \%$ by the simulation and $10.6 \%$ by the exponential model; in depth, $4.9 \%$ by the simulation and $3.7 \%$ by the exponential model; and in area, $1.5 \%$ by the simulation and $3.8 \%$ by the exponential model (Table 6). 


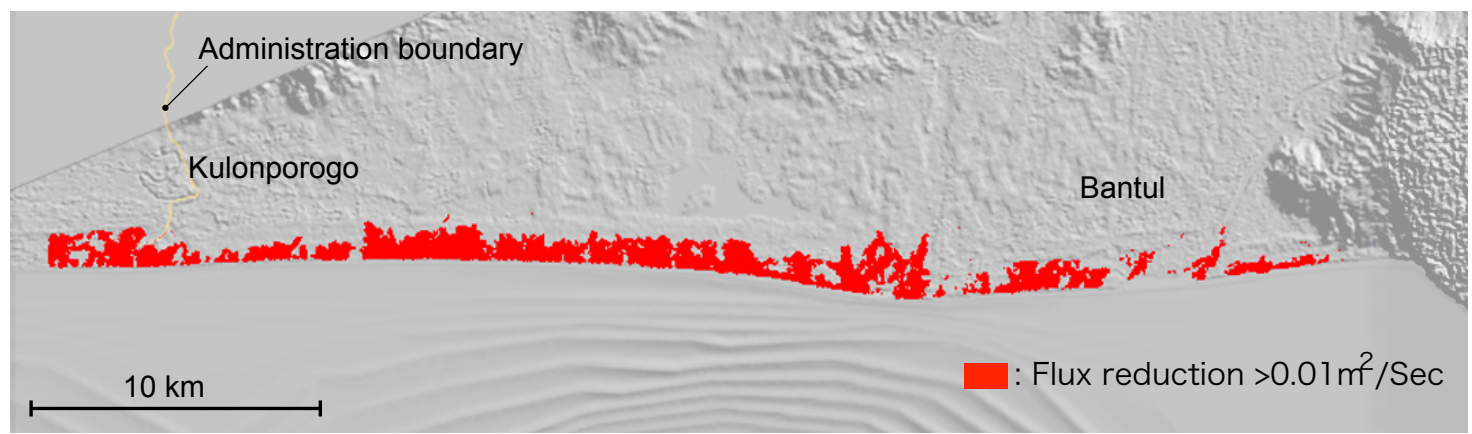

Fig. 13. The area of influence on inundation flux with the plantation.

Table 6. The comparison of transmission by the exponential equation and the simulation.

\begin{tabular}{|c|c|c|c|c|c|c|c|c|c|}
\hline & \multicolumn{3}{|c|}{$\begin{array}{l}\text { Inundation } \\
\text { flux }\end{array}$} & \multicolumn{3}{|c|}{$\begin{array}{l}\text { Inundation } \\
\text { depth }\end{array}$} & \multicolumn{3}{|c|}{$\begin{array}{l}\text { Inundation } \\
\text { area }\end{array}$} \\
\hline & $\begin{array}{r}\text { Exponential } \\
\text { model }\end{array}$ & Simulation & Error & $\begin{array}{r}\text { Exponential } \\
\text { model }\end{array}$ & Simulation & Error & $\begin{array}{r}\text { Exponential } \\
\text { model }\end{array}$ & Simulation & Error \\
\hline Existing forest & $95.4 \%$ & $93.0 \%$ & 2.4 & $98.0 \%$ & $100.0 \%$ & -2.0 & $98.8 \%$ & $94.4 \%$ & 4.4 \\
\hline Existing forest plus plantation & $84.8 \%$ & $83.6 \%$ & 1.2 & $94.2 \%$ & $95.1 \%$ & -0.9 & $95.0 \%$ & $92.9 \%$ & 2.1 \\
\hline Improvement by plantation & $10.6 \%$ & $9.4 \%$ & 1.2 & $3.7 \%$ & $4.9 \%$ & -1.1 & $3.8 \%$ & $1.5 \%$ & 2.3 \\
\hline
\end{tabular}

The total transmissions by exponential models showed a good agreement with those by the numerical simulations. The difference in transmissions after plantation between statistical and numerical models were $1.2,-0.9,2.1 \%$ in flux, depth and area, respectively, against the simulation. This means that the exponential models can predict the impact of coastal forest and plantation on tsunami inundation as good as the numerical model.

\section{Conclusions}

In order to show the role of coastal forest to mitigate the impact of tsunami inundation, the damping behaviors of a coastal forest with varying widths ranging from $20 \mathrm{~m}$ to $200 \mathrm{~m}$ were simulated using a two-dimensional numerical model. The damping effect at the center of post edge of the forest showed highest performance compared to the other areas. The damping effect of forest was evaluated using the average value of water states in the inundation area, including both the forest and the area behind the post edge of forest. The forest range extension could enhance the damping performance, while a $100 \mathrm{~m}$ of forest width could reduce $17.6 \%$ of the inundation flux. Our analyses revealed that the damping effect of forest against tsunami inundation is clearly twodimensional. We also found exponential relationships between forest widths and reductions in inundations. These statistical relationships could potentially be applied for larger areas to quickly evaluate the damping performance of coastal forest even without numerical simulations. We compared the test experiments using simulated topography and results of detail simulations using an actual topography and forest plantation plan and found that quick estimates by the exponential models were accurate and efficient enough for the early stage of planning. Rapid assessment tools of coastal forest impact are exceedingly useful for coastal forest planning that considers several scenarios in their planning and, in particular, their design.

Acknowledgements. We thank Takayuki Aoki, Global Scientific Information and Computing Center, Tokyo Institute of Technology for his assistance in the simulation program. This study is an extension of a project; "Assessment of The Tsunami Mitigation Functions of Coastal Forests/Trees and Proposal for Appropriate Forest Management", carried out by the Japan Wildlife Research Center under the funding of the Forestry Agency, Ministry of Agriculture, Forestry and Fisheries, Japan.

Edited by: H. Sterr

Reviewed by: H. Oumeraci and M. González

\section{References}

Aburaya, T. and Imamura, F.: Tsunami inundation simulation with equivalent roughness coefficient, Jpn. Soc. Civil Eng., 49, 276280, 2002.

BAPEDA: Costal forest planning report, Watershed Management office in Yogyakarta, Indonesia, 2007. 
Bernard, E. N. and Robinson, A. R.: The Sea Tsunamis, Harvard University Press, 15, 321-332, 2009.

Harada, K. and Imamura, F.: Experimental study on the resistance by mangrove under the unsteady flow, Proceeding of the 1st Congress of the Asian and Pacific Coastal Engineering, 975-984, 2000.

Harada, K. and Imamura, F.: Experimental study on the effect in reducing tsunami by the coastal permeable structures, Proceedings of The Twelfth International Offshore and Polar Engineering Conference, 652-658, 2002.

Harada, K. and Imamura, F.: Effects of coastal forest on tsunami hazard mitigation - a preliminary investigation, in: Tsunamis, Advances in natural and technological hazards research, Springer Netherlands, 279-292, 2005.
Kanamori, H.: Mechanism of tsunami earthquakes, Phys. Earth Planet. Int., 6, 346-359, 1972.

Kotani, M., Imamura, F., and Shuto, N.: Tsunami run-up simulation and damage estimation by using GIS, Proceedings of coastal engineering, Jpn. Soc. Civil Eng., 145, 356-360, 1998.

Ohira, W., Kuno, H., Atif, O., and Nonaka, I.: Forest management for mitigation of natural disaster, Indonesia, Japan Wildlife Research Center, Tokyo, Japan, 2009.

Shuto, N.: The effectiveness and limit of tsunami control forests, Coast. Eng. Jpn., 30, 143-153, 1987.

Yanagisawa, H. K., Goto, K., Miyagi, T., Imamura, F., Ruangrassamee, A., and

Tanavud, C.: The reduction effects of mangrove forest on a tsunami based on field surveys at pakarang cape, Thailand and numerical analysis Estuarine, Coast. Shelf Sci., 81, 27-37, 2009. 